\title{
Theoretical Discussion on Forms of Cultural Capital in Singapore
}

This article is a theoretical discussion on five forms of cultural resources that constitute cultural capital for children in the meritocratic yet stratified society of Singapore. These five forms of cultural capital are namely 'academic' tastes and leisure preferences, use of Standard English, access to and dispositions toward information communication technology (ICT), acquisition of learning skills, and confidence/learning dispositions. They cover two important aspects of cultural capital - namely objectified and embodied components - that may vary in levels with social class and that mediate the influence of social class on children's academic achievement. Equally importantly, the focus on one societal context - in this case, Singapore - recognizes the contextual specificities of cultural capital in form and consumption pattern among individuals.

Keywords: cultural capital; meritocracy; Singapore 
In the last decade, Singapore has captured the fascination of policymakers, academics, and students the world over for the stellar performance of its students in a series of international comparative assessments of student learning in English, mathematics, and science (Baer et al. 2007; Bellows 2009; Gonzales et al. 2008; $\underline{\text { Mourshed et al. }}$ 2010; OECD 2010c; Sclafani 2008; Tan 2004). However, a close examination reveals that the academic achievement does not accrue equally to students from different social classes ( $\mathbf{N g}$ and Rothwell 2009) . Furthermore, a review of the literature shows that there is no research that has attempted to identify class-based resources that may influence students’ academic achievement in Singapore. To address this knowledge gap, the objective of this paper is to examine different types of home-based resources that students may leverage on to benefit their learning using a particular perspective - cultural capital theory.

Cultural capital is a sociological construct that has captured the attention of policy-makers and scholars in debates on social inequality and reproduction for decades (MOE 2008a; Bourdieu 1973, 1977; Bourdieu and Passeron 1977, 1979). Originally introduced by Pierre Bourdieu to explain social inequality in French society, the construct has since then been 'exported' in studies examining the same phenomenon in other societies (Bennett et al. 2009; DiMaggio 1982; Holt 1998; $\underline{\text { Jaeger 2009; Katsillis and Rubinson 1990; Lamont and Lareau 1988; Marks and }}$ McMillan 2003; Wu 2008; Yamamoto and Brinton 2010). Whilst cultural capital theory may be useful for the purposes of identifying class-based resources that may impact students' learning, it is important to be cognisant of salient issues that have confronted researchers in this field. Consequently, these issues will be briefly discussed prior to the identification of different forms of cultural capital in the present paper. Accordingly, there are three parts to the discussion. First, the state of social 
stratification and reproduction in Singapore is discussed briefly, and the relevance of cultural capital theory in explaining the stratification of Singapore society is highlighted. In the second section, three different issues that have confronted researchers of cultural capital are discussed. In the third and last section, five forms of cultural capital are identified and discussed, bearing in mind the key issues that are discussed earlier.

\section{Singapore}

Singapore is perhaps synonymous with being an achievement-oriented, meritocratic society where students demonstrate impressive levels of educational achievement (Baer et al. 2007; Bellows 2009; Gonzales et al. 2008; Mourshed et al. 2010; OECD 2010c; Sclafani 2008; Tan 2004). However, as the discussion in this section will show, the overall high level of educational achievement does not preclude the existence of differential relative performance for individuals from different social classes, and the class-based cultural capital that has contribute to these differences. First, system-wide statistics provide compelling evidence of the extent of social mobility in the city state (New chapter in the Singapore Story 2011). For instance, the proportion of citizens aged 25 to 39 who had completed at least secondary school education rose almost fourfold from $25 \%$ in 1980 to $96 \%$ in 2010. This translated to the attainment of educational levels of at least one level above that of their parents for Singaporeans who were born in 1970s/1980s. Another set of statistics showed that the top 5\% of grade 6 students who sat for the mandatory national examination (Primary School Leaving Examination or PSLE) hailed from 95\% of all primary schools and from all socio-economic backgrounds. 
The social mobility in Singapore society may be attributed to the public school system premised on the principles of meritocracy. However, whilst the meritocracy promotes equity of opportunities based on individuals' talents and efforts, it does not necessarily contribute to equality of outcomes. Indeed, according to the Singapore national census conducted in 2010, the Gini coefficient of 0.472 in 2010 signaled gross income inequality in society (MTI 2011). Even when ameliorating social policies like government handouts and taxes were taken into account, the Gini coefficient only improved marginally to 0.452 in 2010, thereby entrenching Singapore's unenviable position as one of the most 'unequal' nations in the developed world (Wilkinson and Pickett 2010). In this light, it is worthwhile to revisit Tan's (2004) assertion that although Singapore may be generally classified as a middle-class society, it is neither 'classless' nor 'one-class'. In fact, his national survey data also showed that there was social reproduction in this stratified society even when there was overall upward social mobility. That social reproduction may occur in an abilitydriven meritocratic society is hardly contradictory ( $\mathrm{Ng} 2007$; $\mathrm{Ng}$ and Rothwell 2009;

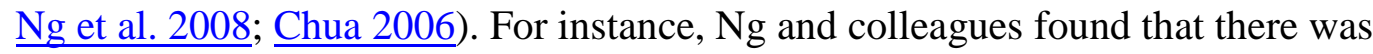
moderately low intergenerational income and earnings mobility in Singapore as compared to many other developed countries (Ng et al. 2008; $\mathrm{Ng}$ and Rothwell 2009). Furthermore, while these researchers acknowledged that universal education had contributed to the levelling up of Singaporeans en masse, they were quick to caution that it 'may not have been as effective as an agent of intergenerational mobility' since 'most of the returns from schooling seem to derive from parents' economic status'. International comparative data from the PISA 2009 study of 15-year-olds’ reading performance also showed that socioeconomic background accounted for a higher 
proportion of their performance (15.3\%) as compared to an average peer from OECD countries (14.0\%) (ECD 2010b).

Singapore is on the one hand, a high-achieving and meritocratic society, and on the other, a stratified society marked by social reproduction. Therefore, it represents an interesting nation to study the different types of class-based advantages possessed by individuals that may influence achievement outcomes and social reproduction. In this respect, cultural capital is attractive as a conceptual heuristic to understand the class-achievement nexus as it has been inextricably associated with social class, inequality, and reproduction. According to cultural capital theory, individuals with cultural capital are ostensibly familiar with the conceptual codes that underlie the tastes and preferences of the middle and high social classes in society. This familiarity is brought about by socialization into legitimate, high-brow culture that occurs naturally within the home of the dominant social class (Bourdieu and Passeron 1977, 1979; De Graaf et al. 2000). These inherited cultural advantages serve as indicators of one's social position and they enable the privileged to enjoy educational advantages in schools that are normatively biased toward individuals conversant with these cultural codes (Bourdieu 1977, 1984; Bourdieu and Passeron 1977, 1979; DiMaggio 1982). Consequently, these advantages translate into positive academic and career outcomes for these privileged individuals. In this manner, cultural capital contributes to social reproduction, thereby perpetuating the cultural advantages of the privileged and entrenching social inequality from one generation to the next. 


\section{Pertinent issues with cultural capital research}

While proponents laud the potential contributions of cultural capital in explaining cultural and social reproduction and inequality, detractors highlight issues with construct conceptualization and measurement, validation of cultural capital theory itself, and the lack of cultural sensitivity in empirical studies (Smith 2001).

\section{Issue 1: Plurality in Conceptualization}

The first issue is that there is plurality in the conceptualization of cultural capital

(Lamont and Lareau 1988; Smith 2001). Many researchers examine one or more of the three interrelated components of Bourdieu's $(\underline{1984}, \underline{1986}, \underline{1998})$ taxonomy -

objectified, embodied, and institutionalized cultural capital (Bennett et al. 2009;

Dumais 2002; Jaeger 2009; Scherger and Savage 2010; Yamamoto and Brinton 2010). Here, objectified cultural capital refers to cultural artifacts while embodied cultural capital refers to the competencies and skills individuals need to appreciate and make meaning of cultural artifacts. Lastly, institutionalized cultural capital is formed when embodied cultural capital is converted into an openly acknowledged form (e.g., academic credentials).

Lamont and Lareau (1988) highlighted the somewhat inconsistent definitions that Bourdieu himself adopted in his writings and proposed their construct of 'institutionalized cultural capital' in lieu of Bourdieu’s. This conceptualization refers to all widely shared high status cultural signals comprising affective (attitudes and preferences), cognitive (formal knowledge), behavioral, objectified, and symbolic (credentials) resources that are used for social and cultural exclusion. Unfortunately, in their endeavor to clarify the conceptual confusion plaguing the literature on cultural capital, Lamont and Lareau had introduced further complexity because their construct 
is so encompassing in its definition that it may be mistaken easily to be a catch-all umbrella term for Bourdieu's three components of cultural capital, of which institutionalized cultural capital is but one.

The diversity in conceptualization of cultural capital has resulted in a plethora of ways that the construct has been measured in studies (Jaeger 2009; $\underline{\text { Vryonides }}$ 2007). Broadly speaking, the myriad of indicators used may be classified into four categories. The first category pertains to parents/children's association with high-brow beaux arts culture. This includes cultural tastes and preferences; cultural familiarity and knowledge; possession of cultural artifacts; and participation in cultural activities (Crook 1997; De Graaf et al. 2000; DiMaggio 1982; DiMaggio and Mohr 1985;

Dimaggio and Mukhtar 2004; Dumais 2002; Jaeger 2009; Katsillis and Rubinson 1990; Roscigno and Ainsworth-Darnell 1999; $\underline{\text { Scherger and Savage 2010; Vryonides }}$ 2007). The second category is related to the availability of resources promoting learning. These resources include parents’ educational qualifications; home educational resources; general home resources that promote learning; and parents and children's reading behavior at home (Crook 1997; De Graaf et al. 2000; Dumais 2002;

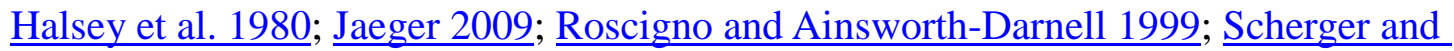
Savage 2010; Vryonides 2007). The third category focuses on children's dispositions consonant with high cultural codes. These include children's physical demeanor; tastes and preferences; attitudes toward the distribution of social resources; perspectives on social issues; and educational and career expectations (Bennett et al. 2009; Dumais 2002; Holt 1998; Smith-Mitchell and Dubelaar 2006). The fourth category revolves around parents' interest and involvement in the learning of their children. It includes parents’ confidence in engaging teachers as equals; discussions with children about school and learning; monitoring of children's learning; knowledge 
of pedagogy, educational system, and school procedures; and involvement in children's education (Gewirtz et al. 1995; Jaeger 2009; Lareau 2000; Lareau and Horvat 1999; McDonough 1997; Reay 1998, 2004; Wegmann and Bowen 2010).

The multidimensional nature of the cultural capital construct means that researchers have to examine as many aspects of the construct in their studies as their resources would permit in a robust research design. Whilst the present paper is not an empirical study, different forms of cultural capital indicative of the myriad aspects of cultural capital will be discussed in the context of Singapore society in the later part of this paper. Whilst not exhaustive, the diversity in the forms of cultural capital discussed is congruent with the rich conceptual meaning of the construct. Consistent with the existing literature, we shall discriminate among different levels of social class using socioeconomic status variables as indicators.

\section{Issue 2: Mixed Results for Internal Validity}

The literature has also failed to consistently provide compelling evidence in support of cultural capital theory (Kingston 2001). To illustrate, two conditions must be met in order to validate the predictive effects of cultural capital on children's achievement (Bourdieu 1973, 1977, 1984, 1986; Bourdieu and Passeron 1977, 1979; Bourdieu and Wacquant 1992; Kingston 2001; Lamont and Lareau 1988). This validation is important as cultural capital theory is propounded to explain social inequality and reproduction, but our theorization can only progress so far as our empirical evidence will take us. The first condition is that children from higher social classes must be demonstrated to possess more cultural capital than peers from lower social classes. This stock of cultural capital must then be able to predict their level of academic achievement, an important predictor of social success and mobility. 
Disappointingly, many of the studies which purport to examine cultural capital do not report on the distribution of cultural capital among children from families of different social classes (Crook 1997; Scherger and Savage 2010; Vryonides 2007). Among the minority that do, many of them do not provide evidence that meet the requirements of the two conditions simultaneously (De Graaf et al. 2000; DiMaggio 1982; Katsillis and Rubinson 1990). For instance, De Graaf and colleagues (2000) found that although parent reading behavior (a measure of cultural capital) predicted children’s reading attainment (a student achievement measure), parents with more years of education did not necessarily had higher levels of reading behavior.

Indeed, there are only a handful of studies that manage to report evidence that meets the requirements of the two conditions (Dumais 2002; Jaeger 2009; Roscigno

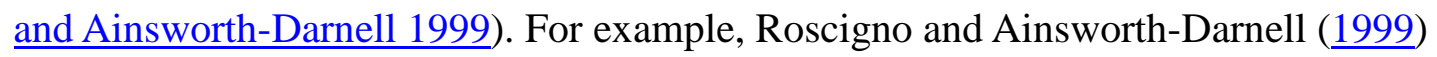
found that social class was positively associated with levels of cultural capital - as measured by children's participation in cultural trips and cultural classes and the availability of household educational resources - that in turn predicted children's outcomes. In view of the requirement for associations amongst cultural capital, social class, and academic achievement, empirical evidence will be reviewed in later sections of this article to support the argument that the different forms of cultural resources expounded do indeed qualify as cultural capital in the Singapore context.

\section{Issue 3: Lack of Cultural Sensitivity}

There is also a lack of cultural sensitivity apparent in some of the studies. Paradoxically, this problem may be attributed to the ubiquitous fascination with and wholesale export of Bourdieu's theory to regions as diverse as Europe, the United States, Australia, and Asia (Bennett et al. 2009; $\underline{\text { Holt 1998; Marks and McMillan }}$ 2003; Yamamoto and Brinton 2010). Quite predictably, many of these studies produce 
mixed results on the specific forms of cultural capital that have an impact on children’s academic achievement (De Graaf et al. 2000; Katsillis and Rubinson 1990;

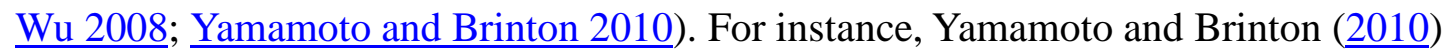
found that the presence of objectified cultural capital at home predicted the quality of high school children attended, but not their academic performance, for their Japanese sample. They also found that children's participation in fine arts activities with their parents predicted the quality of high school they attended and their academic performance, but not their educational attainment. In contrast to objectified cultural capital or fine arts participation, parents' reading to their children failed to predict all of the outcomes measured, namely the quality of high school they attended, academic performance, or educational attainment.

In response to this dismal state of evidence, some scholars have attempted to ‘indigenize’ their conceptualization of cultural capital to suit the socioeconomic

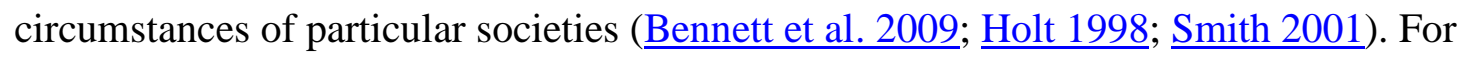
example, Bennett and colleagues (2009) concluded from their large-scale study of cultural patterns in the United Kingdom that it is more meaningful to differentiate social classes in terms of cultural consumption patterns than content. Furthermore, they found that class did not explain cultural consumption patterns as strongly as expected, plausibly because class preferences and tastes overlapped in some cultural fields, there was less class consciousness, and there was greater acceptance of cultural diversity associated with different classes in the society they were studying. In line with the emic perspective to cultural capital theory, discussion of the different forms of cultural capital in the following sections will be framed in the Singapore context.

\section{Cultural capital in Singapore}


The aforementioned issues with cultural capital research discussed highlight the importance for researchers to take cognizance of these issues and address them in their research. Indeed, the potential of different forms of cultural capital in explaining social inequality and reproduction would be enhanced if they (a) reflect the myriad nature of the construct - objectified, embodied, and/or institutionalized, wherever possible; (b) vary in levels with social class and mediate the influence of social class on children's academic achievement; and (c) reflect the particularistic nature of the society under examination. In the following section, different forms of cultural capital relevant to the Singapore context are identified and discussed, bearing in mind these three attributes. The aim is to examine the different forms of cultural capital that may have contributed to social inequality in this nation. These forms of cultural capital are namely, 'academic' tastes and preferences in leisure activities, use of Standard English, access to and dispositions toward ICT, acquisition of learning skills, and confidence/learning dispositions. Admittedly, these forms of capital are by no means exhaustive, but they are used to illustrate salient aspects of cultural capital that are relevant in the Singapore context. They represent a spectrum of cultural resources that correspond to two different Bourdieuian aspects of cultural capital -objectified and embodied capital. ${ }^{1}$ These forms of capital are highly valued in the achievement-driven Singapore society where parents devote much resources to ensuring that their children prefer academic to non-academic pursuits, speak Standard English so as to excel in examinations, harness ICT to enhance academic learning, master pro-learning skills, and exhibit passion and confidence in academic learning, in the hope that their

$\square$ Many of these forms of capital pertain to embodied cultural capital that should be contrasted with habitus, a closely related concept in cultural capital theory that also measure individuals' dispositions, but pertaining more to education/career aspirations and plans, and self-efficacy in achieving these aspirations and plans (Engberg and Wolniak 2010; Cerna et al. 2009; Salisbury et al. 2009; Pearce and Lin 2007; Pearce and Zeng 2005; Perreira et al. 2006; Nora 2004; Dumais 2002). 
children will excel in high-stake national examinations. At the same time, the emphasis of the centrally controlled Singapore school curriculum to deliver the socalled Desired Outcomes of Education (e.g.. confident persons who can articulate their opinions, self-directed learners who are able to leverage on ICT for learning, and individuals who are able to learn collaboratively in teams; MOE 2011) further underscores the benefits that students possessing these cultural capital forms will have in their academic pursuits.

Equally important, the forms of cultural capital to be discussed are selected because a review of the literature suggests that these variables may each be correlated with social class and academic achievement simultaneously. Obviously, there may be other forms of cultural capital relevant to the Singapore context, but the scarcity of empirical evidence in the current literature relating them to social class and academic achievement precludes their inclusion in this article. It should also be qualified that these forms of cultural capital vary in their degree of uniqueness to Singapore society - for example, while the use of Singlish is a distinctively Singaporean manifestation, access to and dispositions toward ICT may apply equally to other advanced economies. At the other extreme of the spectrum, learning dispositions may be congeneric across various societal contexts at different stages of development.

\section{Academic Tastes and Preferences in Leisure}

The first form of cultural capital in the Singapore context is parents' academic tastes and leisure preferences. It is reasonable to assume that children may benefit from their parents' tastes and preferences which vary as a function of social class. Evidence from a study of a large-scale representative sample of Singaporeans' values, lifestyles, aspirations, and consumption behaviors showed that compared to respondents who 
had primary education or less, a greater proportion of more highly educated respondents (post-secondary or higher) read local and foreign newspapers and current affairs magazines, and watched television documentaries (Kau et al. 2004). Plausibly, children who grow up in these households where more highly educated parents read and watch more academic, as opposed to entertainment, content will reap educational benefits if their parents were to use the knowledge and insights gleaned from these media in their interactions with their children (Chiu and Chow 2010; Jaeger 2009; Marjoribanks 2005). When these children exhibit a high level of awareness of sociocultural and scientific issues in their interactions with teachers, they will be able to engage the latter more confidently. This earns them increased attention and admiration from teachers. Consequently, these benefits may translate to higher levels of academic achievement for them in school.

\section{Use of Standard English}

It is not difficult to conjecture that children from higher social classes who have the benefit of continuous exposure to such academic reading and television materials, especially those communicated in the English language, and daily interaction opportunities with more linguistically competent parents will have a stronger command of Standard English over time. The mastery of Standard English is important in the context of multiracial, multilingual Singapore, as it is the official lingua franca in education, work, commerce, and government. Sociolinguists have examined the competent use of Standard English, as opposed to colloquial English (or Singlish), as a form of embodied cultural capital enjoyed by children from higher social classes in Singapore (Alsagoff 2007, 2010; Gupta 1992, 1994; $\underline{\text { Ho and Platt }}$ 1993; Pakir 1991; Platt and Weber 1980). For example, Platt and colleagues differentiated among four forms of English used that varied with proficiency levels 
and social classes of users using the lectal continuum model (Platt and Weber 1980;

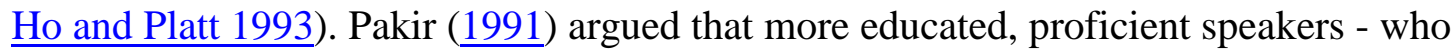
command a range of formal and informal linguistic styles, and who are able to use the appropriate style in different situations - are able to use Standard English whereas less educated, rudimentarily proficient speakers who are not capable of participating in contexts requiring a high level of linguistic formality may use Singlish instead. More recently, Alsagoff (2007, 2010) suggested that Singaporeans who use Standard English in their interactions are individuals who have the desire to excel in the global marketplace and acknowledge that English is the endorsed lingua franca.

These sociolinguistic perspectives underscore the influence of class and privilege, in that individuals from a higher social class - as measured by socioeconomic status, globalized outlook, and rich linguistic styles - tend to be more conversant with Standard English than their peers who are from a lower social class. Consequently, when these users of Standard English pass on these cultural advantages to their children, it is only to be expected that their children will more likely meet teachers' academic expectations in the command of Standard English or proficiency of other subjects taught in Standard English (Hampden-Thompson and Johnson 2006). Indeed, there is empirical evidence that children who come from homes where English is the language most spoken tend to have higher levels of educational attainment if the language of instruction in the education system is English (Perna 2004). Hence, it is difficult not to concur with Alsagoff's (2007) contention that 'the variation in Singapore English is not one of choice, but one of access and opportunity’. 


\section{Information Communication Technology}

The third form of cultural capital takes into account individuals' learning via ICT. Indeed, data show that ICT deepens the socioeconomic gap and contributes to the infamous 'digital divide' between the endowed and deprived at two levels (SmithMitchell and Dubelaar 2006; OECD 2010a; Korupp and Szydlik 2005). At one level, individuals from higher social classes have greater access to computers, the Internet, and ICT-enabled learning experiences than their peers from lower social classes. Evidence for this difference in access is shown by national level data on household expenditure in Singapore (MTI 2009) illustrating that among Singaporeans living in households with an income in the bottom quintile, only $48.6 \%$ had access to either laptop or computer at home - as opposed to $93.3 \%$ of their peers from households with an income in the top quintile. The data also illustrated that only $17.1 \%$ of Singaporeans living in the smallest government flat (1- to 2-room) had access to either laptop or computer at home as compared with $57.2-91.7 \%$ of their peers living in larger government flats, or 92.6\% of individuals who live in private housing (private flats or landed properties).

Even if access rates to ICT between the different social classes were to converge over time, individuals from higher social classes may continue to outperform their peers from lower social classes because of attitudinal differences in technological consumption ( $\underline{\text { Smith-Mitchell and Dubelaar 2006; Kvasny and Truex }}$ 2000; OECD 2010a). For example, Smith-Mitchell and Dubelaar (2006) found that individuals from lower social classes used ICT for functional purposes whereas individuals from higher social classes appreciated ICT for its facilitation and provision of new opportunities in addition to its functional utility. Furthermore, while individuals from lower social classes relied on ICT for information in an 
unquestioning fashion, their peers from higher social classes compared the veracity of the information obtained with that available from traditional sources before making informed decisions. In this regard, one’s attitudes - as exemplified by expectations, aspirations, and attitudes toward technology - not only influences one’s consumption but also understanding of technology (Kvasny and Truex 2000).

It follows that differences in ICT access and attitudes among individuals from different social classes may translate to educational advantages for the privileged. Support for this argument is borne out in the PISA study conducted in 2006 (OECD 2010a). The evidence showed that ICT user profiles were largely a function of social class in developed OECD countries. In particular, children from the highest social class, the Digi-wired, were more confident in Internet tasks like chatting online, searching for information online, downloading files, attaching files to emails, and downloading music than their peers from the lowest social class, the Digieducationals. Not surprisingly, the Digi-wired children also had higher levels of science performance than the Digi-educationals children. In the Singapore context, enhanced access to (objectified capital) and competence in using ICT (embodied capital) will undoubtedly complement children's learning in schools in the nationwide ICT initiative to empower children's learning using innovative technologies since 1997, and contribute toward schools' endeavor to develop self-directed learners in the Desired Outcomes of Education (MOE 2008b, 2011).

\section{Skills Facilitating Learning}

The fourth and fifth forms of cultural capital relate to embodied skills and dispositions that facilitate learning respectively. Consideration of skills and dispositions as manifestations of cultural capital is consistent with the view that cultural capital includes a plethora of widely shared, high status cultural signals that are used for 
social and cultural exclusion (Lamont and Lareau 1988). These skills and dispositions are inextricably fused with the concept of cultural capital in Bourdieu's work and rewarded by teachers in schools (Farkas 1996; Lareau and Weininger 2003).

Indeed, there is evidence that children from a higher social class may be more likely to acquire these skills as compared to peers from a lower social class. In a large-scale longitudinal study of students in Singapore schools, Hogan and Kang (2006) found that students from the highest socioeconomic quartile possessed higher levels of different skills than their peers from the lowest socioeconomic quartile. These skills comprised interpersonal problem-solving, social and leadership, multiliteracy, and interdisciplinary skills. Of these four types of skills, multi-literacy and interdisciplinary skills may be argued to contribute toward academic achievement most directly since students must demonstrate mastery of two languages - Standard English and a mother tongue language - and understand connections among content taught in different subjects in the Singapore educational system. Thus, it is not an extrapolation to hypothesize that children from higher social classes may perform better than their less privileged peers because of their cultural repertoire of learning skills. In fact, there is empirical evidence that children who have higher levels of measures on learning to approaches (i.e., attentiveness, task persistence, eagerness to learn, learning independence, flexibility, and organization in learning) and interpersonal skills are associated with higher levels of reading skills in school (Condron 2007). Children equipped with these pro-learning skills are also aligned with schools' effort to develop individuals who can work with peers in teamwork, who exhibit initiative, who are innovative, and who pursue excellence in their learning (MOE 2011). This alignment means that these children will be able to benefit from what is emphasized in the school curriculum. 


\section{Confidence and Learning Dispositions}

The last form of cultural capital discussed pertains to confidence and learning dispositions as another form of embodied cultural capital. Support for this argument is available from the large-scale longitudinal study of students in Singapore schools by Hogan and Kang (2006). In that study, the researchers found that students from the top socio-economic quartile had higher levels of confidence as measured by selfefficacy, locus of control, agency, optimism, and educational aspirations than their peers from the bottom socio-economic quartile. These attitude measures, with the exception of educational aspirations, appear to relate more to embodied cultural capital, instead of two other closely related concepts in cultural capital theory habitus and human capital. Habitus measures individuals' dispositions, but it pertains more to education/career aspirations and plans, and self-efficacy in achieving these aspirations and plans (Engberg and Wolniak 2010; Cerna et al. 2009; Salisbury et al. 2009; Pearce and Lin 2007; Pearce and Zeng 2005; Perreira et al. 2006; Nora 2004; Dumais 2002). Admittedly, educational aspirations may also be interpreted as a proxy for intended human capital accumulation. Nonetheless, the various confidence and learning dispositions in Hogan and Kang’s study are taken to measure general embodied cultural capital as most of them are related to competencies and skills individuals need to appreciate and make cultural meaning in their academic pursuits. In Hogan and Kang's study, students from the top socioeconomic quartile embraced project work, collaborative work, and competition better, and they had a greater propensity to engage in both individual and group tasks than their less privileged peers. Students from the top socioeconomic quartile were also more accepting of societal distribution of rewards based on academic merit than their peers from the bottom socioeconomic quartile. In turn, this may result in the former having a greater 
propensity to learn and excel academically. They are also more persevering in their academic endeavors and more likely to experience academic success in schools.

\section{Conclusion}

The aim of this article is to provide a theoretical discussion on different forms of cultural capital in a specific societal context - Singapore. The discussion has focused on how children from different social classes may have different levels of cultural capital - as exemplified by academic tastes and preferences in leisure activities, use of Standard English, access to and dispositions toward ICT, acquisition of learning skills, and confidence/learning dispositions - and how these different forms of cultural capital may give them a cultural advantage in their academic pursuits. The identification of a variety of cultural resources acknowledges the diverse conceptualization and operationalization in the cultural capital literature. There is also a deliberate effort to identify only cultural resources that vary in levels with the social class of children and that may predict their academic achievement. This approach addresses the confusion in the literature where different resources may be classified as cultural capital even when there is no evidence that they correlate with social class and academic achievement (Kingston 2001). Equally important, framing the discussion in the context of Singapore gives it cultural specificity, as previous studies have demonstrated that the forms and consumption of cultural capital may vary from one society to another (Bennett et al. 2009; Holt 1998; Smith 2001).

One important implication that follows from this discussion pertains to social and education policy. Identification of the five forms of cultural capital discussed implies that policy-makers have additional leverage points, over and above economic assistance, to bridge the educational deficits of children from lower social classes. Specifically, this means schools and social service agencies can adopt a two-prong 
approach to improving academic performance of disadvantaged students. First, they can address economic deficits these students face, like integrating in the school curriculum visits to the school library, newspapers reading, and computer lessons; and providing financial assistance to these students. Second, with these socioeconomic provisions in place, schools can then consider promoting more selective reading and television viewing habits, the use of Standard English, access to and the informed use of ICT, the learning of various pro-learning skills, and the acquisition of positive prolearning dispositions. Since the acquisition of learning skills and positive dispositions are often pontificated to be requisite skills that knowledge workers will need in the workforce (Ng 2007), schools and society at large should emphasize them, beyond the mere provision of equal opportunities, in any bona fide meritocracy as Chua (2006) has opined.

The second implication is that, similar to the approach illustrated in this paper, cultural capital researchers should make an effort to examine society-specific cultural resources and demonstrate that these resources are associated with both social class and children's academic achievement in the expected direction. These resources can be labeled as cultural capital only after it has been established that children from higher social classes do indeed possess higher levels of these resources which mediate the relationship between social class and children's academic achievement. This approach builds on the rich conceptualization of cultural capital in the literature and provides a more robust validation of the capital-outcome relationship in different cultural contexts in an increasingly diverse world. Indeed, a potential research program will comprise the investigation of first, the socioeconomic status distribution of a nationally representative sample of parents to ascertain the degree of social stratification in Singapore society. These parents and their children should then be 
surveyed on their possession of the five forms of cultural capital discussed in this article over time. Concomitantly, the academic achievement of the children of these parents should be tracked longitudinally whilst they are still in school. At the school level, the premium that school principals and teachers place on learning associated with these forms of cultural capital (e.g., students having an academic orientation, mastery of Standard English, ICT-enabled learning, Desired Outcomes of Education) can also be measured. Evidence of the mediating effects of the five forms of cultural capital in the socioeconomic status-academic achievement relationship, coupled with schools' emphasis on learning associated with these forms of cultural capital, will constitute empirical support for the validity of these forms of cultural capital as mechanisms for social stratification and reproduction over time. 


\section{References}

Alsagoff, L. (2007). Singlish: Negotiating culture, capital and identity. In V. Vaish, S. Gopinathan, \& Y. Liu (Eds.), Language, capital, culture: Critical studies of language and education in Singapore (pp. 25-45). Rotterdam: Sense.

Alsagoff, L. (2010). English in Singapore: culture, capital and identity in linguistic variation. World Englishes, 29(3), 336-348.

Baer, J., Baldi, S., Ayotte, K., \& Green, P. (2007). The reading literacy of U.S. fourthgrade students in an international context: Results from the 2001 and 2006 Progress in International Reading Literacy Study (PIRLS) (NCES 2008-017). Washington, DC National Center for Educational Statistics, Institute of Education Sciences, U. S. Department of Education.

Bellows, T. J. (2009). Meritocracy and the Singapore political system. Asian Journal of Political Science, 17(1), 24-44, doi:10.1080/02185370902767581.

Bennett, T., Gayo-Cal, M., Savage, M., Silva, E. B., Warde, A., \& Wright, D. (2009). Culture, class, distinction. London: Routledge.

Bourdieu, P. (1973). Cultural reproduction and social reproduction. In R. Brown (Ed.), Knowledge, education, and cultural change: papers in the sociology of education (pp. 71-112). London: Tavistock.

Bourdieu, P. (1977). Cultural reproduction and social reproduction. In J. Karabel, \& A. H. Halsey (Eds.), Power and ideology in education (pp. 487-511). New York, NY: Oxford University Press.

Bourdieu, P. (1984). Distinction: a social critique on the judgment of taste. Cambridge, MA: Harvard University Press. 
Bourdieu, P. (1986). The forms of capital. In J. G. Richardson (Ed.), Handbook of theory and research for the sociology of education (pp. 241-258). New York, NY: Greenwood.

Bourdieu, P. (1998). Practical reason: on the theory of action. Cambridge, MA: Polity Press.

Bourdieu, P., \& Passeron, J. C. (1977). Reproduction in education, society and culture. Beverly Hills, CA: Sage.

Bourdieu, P., \& Passeron, J. C. (1979). The Inheritors, French students and their relation to culture. Chicago, IL: University of Chicago Press.

Bourdieu, P., \& Wacquant, L. J. D. (1992). An invitation to reflexive sociology. Chicago, IL: University of Chicago Press.

Cerna, O. S., Perez, P. A., \& Saenz, V. (2009). Examining the precollege attributes and values of Latina/o Bachelor's degree attainers. Journal of Hispanic Higher Education, 8(2), 130-157.

Chiu, M. M., \& Chow, B. W. Y. (2010). Culture, motivation, and reading achievement: High school students in 41 countries. Learning and Individual Differences, 20(6), 579-592.

Chua, B. H. (2006). Values and development in Singapore. In L. E. Harrison, \& P. L. Berger (Eds.), Developing cultures: Case studies (pp. 101-118). New York and London: Routledge.

Condron, D. J. (2007). Stratification and educational sorting: Explaining ascriptive inequalities in early childhood reading group placement. Social Problems, 54(1), 139-160, doi:10.1525/sp.2007.54.1.139.

Crook, C. J. (1997). Cultural practices and socioeconomic attainment: The Australian experience. Westport, CT: Greenwood Press. 
De Graaf, N. D., De Graff, P. M., \& Kraaykamp, G. (2000). Parental cultural capital and educational attainment in the Netherlands: A refinement of the cultural capital perspective. Sociology of Education, 73(2), 92-111.

DiMaggio, P. (1982). Cultural capital and school success: the impact of status culture participation on the grades of U.S. high school students. American Sociological Review, 47(2), 189-201.

DiMaggio, P., \& Mohr, J. (1985). Cultural capital, educational attainment, and marital selection. American Journal of Sociology, 90(6), 1231-1261.

Dimaggio, P., \& Mukhtar, T. (2004). Arts participation as cultural capital in the United States, 1982-2002: Signs of decline? Poetics, 32, 169-194.

Dumais, S. A. (2002). Cultural capital, gender, and school success: the role of habitus. Sociology of Education, 75(1), 44-68.

Engberg, M. E., \& Wolniak, G. C. (2010). Examining the effects of high school contexts on postsecondary enrollment. Research in Higher Education, 51(2), 132-153.

Farkas, G. (1996). Human capital or cultural capital? Ethnicity and poverty groups in an urban school district. New York, NY: Aldine De Gruyter.

Gewirtz, S., Ball, S. J., \& Bowe, R. (1995). Markets, choice and equity in education. Buckingham: Open University Press.

Gonzales, P., Williams, T., Jocelyn, L., Roey, S., Kastberg, D., \& Brenwald, S. (2008). Highlights from TIMSS 2007: Mathematics and science achievement of U. S. fourth- and eighth-grade students in an international context (NCES 2009-001 Revised) Washington, DC: National Center for Education Statistics, Institute of Education Sciences, U. S. Department of Education. 
Gupta, A. F. (1992). Contact features of Singapore Colloquial English. In K. Bolton, \& H. Kwok (Eds.), Sociolinguistics today (pp. 323-345). London: Routledge.

Gupta, A. F. (1994). A framework for the analysis of Singapore English. In S. Gopinathan, A. Pakir, W. K. Ho, \& V. Saravanan (Eds.), Language, society and education in Singapore: Issues and trends (pp. 119-132). Singapore: Times Academic Press.

Halsey, A. H., Heath, A. F., \& Ridge, J. M. (1980). Origins and destinations. Oxford: Clarendon Press.

Hampden-Thompson, G., \& Johnson, J. S. (2006). Variation in the relationship between nonschool factors and student achievement on international assessments (NCES 2006-014). Washington, DC: Institute of Education Sciences, U.S. Department of Education.

Ho, M. L., \& Platt, J. (1993). Dynamics of a contact continuum: Singaporean English. Oxford: Clarendon Press.

Hogan, D., \& Kang, T. (2006). Toward talentocracy: Capital formation among young Singaporeans. In A. E. Lai (Ed.), Singapore perspectives 2006 (Going glocal: Being Singaporean in a globalised world (pp. 31-50). Singapore: Marshall Cavendish Academic.

Holt, D. B. (1998). Does cultural capital structure American consumption? Journal of Consumer Research, 25(1), 1-25, doi:http://www.journals.uchicago.edu/JCR/home.html.

Jaeger, M. M. (2009). Equal access but unequal outcomes: cultural capital and educational choice in a meritocratic society. Social Forces, 87(4), 1943-1971. 
Katsillis, J., \& Rubinson, R. (1990). Cultural capital, student achievement, and educational reproduction: The case of Greece. American Sociological Review, 55(2), 270-279.

Kau, A. K., Jung, K., Tambyah, S. K., \& Tan, S. J. (2004). Understanding Singaporeans: Values, lifestyles, aspirations and consumption behaviors. Singapore: World Scientific.

Kingston, P. W. (2001). The unfulfilled promise of cultural capital theory. Sociology of Education, 74(4), 88-99.

Korupp, S. E., \& Szydlik, M. (2005). Causes and trends of the digital divide. European Sociological Review, 21(4), 409-422.

Kvasny, L., \& Truex, D. (2000). Information technology and the cultural reproduction of social order: A research paradigm. In R. Baskerville, J. Stage, \& J. L. DeGross (Eds.), Organizational and social perspectives on information technology (pp. 277-293). Boston, MA: Kluwer Academic.

Lamont, M., \& Lareau, A. (1988). Cultural capital: allusions, gaps and glissandos in recent theoretical developments. Sociological Theory, 6(2), 153-168.

Lareau, A. (2000). Home advantage: Social class and parental intervention in elementary education (second edition). Oxford: Rowman and Littlefield.

Lareau, A., \& Horvat, E. M. (1999). Moments of social inclusion and exclusion: Race, class, and cultural capital in family-school relationships. Sociology of Education, 72(1), 37-53.

Lareau, A., \& Weininger, E. B. (2003). Cultural capital in educational research: a critical assessment. Theory \& Society, 32(5/6), 567-606.

Marjoribanks, K. (2005). Family environments and children's outcomes. Educational Psychology, 25(6), 647-657. 
Marks, G. N., \& McMillan, J. (2003). Declining inequality? The changing impact of socio-economic background and ability on education in Australia. The British Journal Of Sociology, 54(4), 453-471.

McDonough, P. (1997). Choosing college: How social class and schools structure opportunity. Albany, NY: State University of New York Press.

MOE (2008a). Equal chances for all.

http://www.moe.gov.sg/media/forum/2008/08/equal-chances-for-all.php. Accessed January 112013.

MOE (2008b). MOE launches third masterplan for ICT in education.

http://www.moe.gov.sg/media/press/2008/08/moe-launches-third-

masterplan.php. Accessed January 112013.

MOE (2011). Desired outcomes of education.

http://www.moe.edu.sg/education/desired-outcomes/. Accessed September 7 2011.

Mourshed, M., Chijioke, C., \& Barber, M. (2010). How the world's most improved school systems keep getting better.

http://ssomckinsey.darbyfilms.com/reports/EducationBookNov23.pdf.

Accessed June 62011.

MTI (2009). Report on the Household Expenditure Survey 2007/08. Singapore:

Department of Statistics, MTI.

MTI (2011). Key household income trends, 2010. Singapore: Department of Statistics, MTI.

New chapter in the Singapore Story. (2011, March 8). The Straits Times. 
Ng, I. Y. H. (2007). Intergenerational income mobility in Singapore (Topics: Article 3). The B. E. Journal of Economic Analysis \& Policy, 7. http://www.bepress.com/bejeap/vol7/iss2/art3. Accessed March 212011.

Ng, I. Y. H., \& Rothwell, D. (2009). A rising tide lifts no sunken boat. Social Space, 2, 92-98.

Ng, I. Y. H., Shen, X., \& Ho, K. W. (2008). Intergenerational earnings mobility in Singapore and the United States (Working Paper Series No. 2008/03). Singapore: Economic Growth Centre, Nanyang Technological University. Nora, A. (2004). The role of habitus and cultural capital in choosing a college, transitioning from high school to higher education, and persisting in college among minority and nonminority students. Journal of Hispanic Higher Education, 3(2), 180-208.

OECD (2010a). Are the new millennium learners making the grade? Technology use and educational performance in PISA. Paris: Centre for Educational Research and Innovation, OECD.

OECD (2010b). PISA 2009 results: overcoming social background - Equity in learning opportunities and outcomes (Volume II). http://dx.doi.org/10.1787/9789264091504-en. Accessed August 272012.

OECD (2010c). PISA 2009 results: What students know and can do - Student performance in reading, mathematics and science (Volume I). http://dx.doi.org/10.1787/9789264091450-en. Accessed June 62011.

Pakir, A. (1991). The range and depth of English-knowing bilinguals in SIngapore. World Englishes, 10(2), 167-179. 
Pearce, R. R., \& Lin, Z. (2007). Chinese American post-secondary achievement and attainment: A cultural and structural analysis. Educational Review, 59(1), 1936.

Pearce, R. R., \& Zeng, L. (2005). Cultural capital and postsecondary educational attainment among white and Chinese Americans: An analysis of NELS 19882000. Asian American Policy Review, 14, 19-37.

Perna, L. W. (2004). Understanding the decision to enroll in graduate school: Sex and racial/ethnic group differences. Journal of Higher Education, 75(5), 487-527.

Perreira, K. M., Harris, K. M., \& Lee, D. (2006). Making it in America: high school completion by Immigrant and native youth. Demography, 43(3), 511-536, doi:http://muse.jhu.edu/journals/demography/.

Platt, J., \& Weber, H. (1980). English in Singapore and Malaysia: Status, features, functions. Kuala Lumpur: Oxford University Press.

Reay, D. (1998). Class work: Mothers' involvement in their children's primary schooling. London: University College Press.

Reay, D. (2004). Education and cultural capital: The implications of changing trends in education policies. Cultural Trends, 13(50), 73-86, doi:10.1080/0954896042000267161.

Roscigno, V. J., \& Ainsworth-Darnell, J. W. (1999). Race, cultural capital, and educational resources: Persistent inequalities and achievement returns. Sociology of Education, 72(3), 158-178.

Salisbury, M. H., Umbach, P. D., Paulsen, M. B., \& Pascarella, E. T. (2009). Going global: Understanding the choice process of the intent to study abroad. Research in Higher Education, 50(2), 119-143. 
Scherger, S., \& Savage, M. (2010). Cultural transmission, educational attainment and social mobility. The Sociological Review, 58(3), 406-428, doi:10.1111/j.1467954X.2010.01927.x.

Sclafani, S. K. (2008). Two roads to high performance. Educational Leadership, 66(2), 26-30.

Smith-Mitchell, E., \& Dubelaar, C. (2006). The Internet: Leveler or divider? A cultural capital perspective. American Marketing Association, Winter, 160167.

Smith, P. (2001). Cultural theory: An introduction. Malden, MA: Blackwell.

Tan, E. S. (2004). Does class matter? Social stratification and orientations in Singapore. Singapore: World Scientific.

Vryonides, M. (2007). Social and cultural capital in educational research: Issues of operationalisation and measurement. British Educational Research Journal, 33(6), 867-885.

Wegmann, K., \& Bowen, G. L. (2010). Strengthening connections between schools and diverse families: A cultural capital perspective. Prevention Researcher, 17(3), 7-10.

Wilkinson, R., \& Pickett, K. (2010). The spirit level: Why equality is better for everyone. London: Penguin.

Wu, Y. (2008). Cultural capital, the state, and educational inequality in China, 19491996. Sociological Perspectives, 51(1), 201-227, doi:10.1525/sop.2008.51.1.201.

Yamamoto, Y., \& Brinton, M. C. (2010). Cultural capital in East Asian educational systems: The case of Japan. Sociology of Education, 83(1), 67-83. 